\title{
Multiple myeloma presenting as the Collet-Sicard syndrome
}

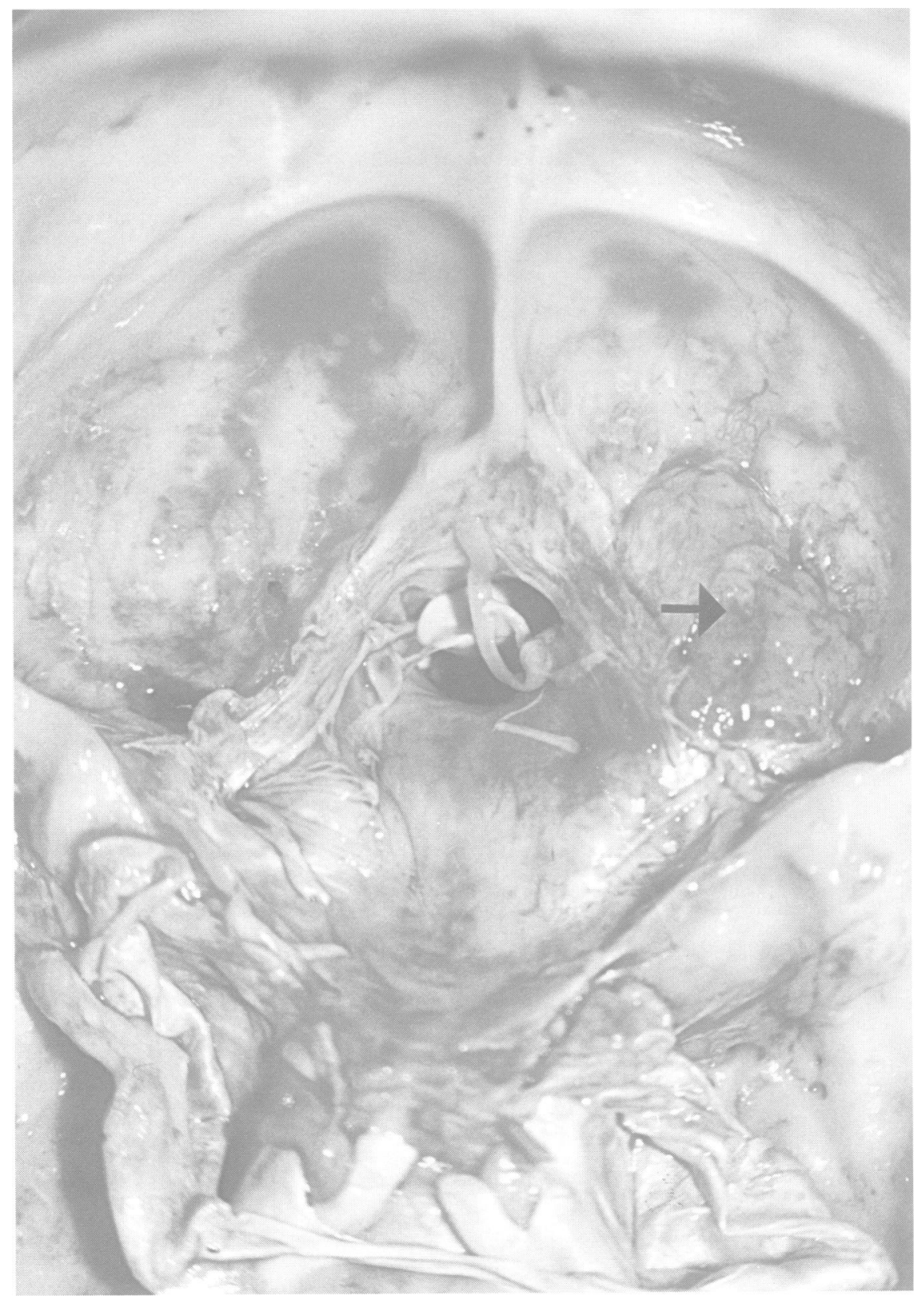

Multiple myeloma presenting with a neurological lesion is a well recognised phenomenon. ${ }^{1}$ Presentation with a cranial nerve lesion, however, is uncommon. This fifty two year old man presented with weight loss, fever, dehydration, and lesions involving the 9 th, 10 th, 11 th , and 12 th cranial nerves on the left side. This lesion complex is often referred to as the Collet-Sicard syndrome. A diagnosis of multiple myeloma was subsequently made. The patient later died of pneumonia.

Postmortem examination disclosed a soft, pink, extradural mass $2 \times 2 \times 1 \mathrm{~cm}$ entering into the adjacent apex of the petrous temporal bone (see arrow). Histological examination confirmed the mass as a myelomatous deposit.

J A TAPPIN JA CORLESS F ASHWORTH Department of Haematology, Whiston Hospital, Merseyside, UK

Correspondence to: Dr J A Corless, 21 Arnside Avenue, Rainhill, Merseyside L35 9JH, UK.

1 Silverstein A, Doniger PE. Neurological complications of myelomatosis. Arch Neurol 1963;9:534-44.

Neurological pictures of striking signs, radiographs, or micrographs may be submitted to the Editor. 